\title{
A Pediatric Aortic Dissection with Cerebral Bleed: A Review in Diagnosis and Management
}

\author{
Cameron SD', Biliciler-Denktas Gurur ${ }^{2}$, Douglas $\mathbf{W I}^{2}$, Srinivasan $\mathrm{A}^{2}$ and Rafique $\mathbf{M B}^{4 *}$ \\ ${ }^{1}$ Department of Anesthesiology, University of Texas Health Science Center Houston, Houston, TX 77030, USA \\ ${ }^{2}$ University of Texas Health Science Center Houston, Houston, TX 77030, USA \\ ${ }^{3}$ Department of Radiology, Children's Hospital of Pittsburgh, Pittsburgh, PA 15224, USA \\ ${ }^{4}$ University of Texas Health Science Center Houston, Houston, TX, USA
}

\begin{abstract}
Trauma in children is major cause of morbidity and mortality and motor vehicle accident (MVA) is the most common cause of blunt trauma. Often times multiple organ systems are affected in MVA e.g. chest injury accompanied by head injury or abdominal visceral rupture. Thoracic vascular injury is rare in children but can prove life threatening if not treated promptly. The diagnosis of such injuries poses a challenge and sometimes different diagnostic modalities could show contradicting diagnosis. In such a situation it may be prudent to do further investigation with another modality; but clinical condition has to be taken into consideration.
\end{abstract}

Keywords: Pediatric; Aortic dissection; Cerebral bleed; Diagnosis

\section{Introduction}

Approximately one-third of all hospital admissions in the U.S. are trauma-related. Trauma is major source of morbidity and mortality in children. Children account for $25 \%$, of trauma admissions, with a resultant 200,000 hospitalizations and 10,000 deaths annually. The National Pediatric Trauma Registry reports that $40 \%$ of cases are a result of motor vehicle accidents (MVA); other common causes include bicycle injuries and falls [1]. Head trauma is the leading cause of death among children, followed by chest trauma [2].

The most common cause of chest injury is blunt trauma $[3,4]$. Blunt chest trauma is most commonly due to MVA, while falls and abuse comprise a minority. Children under age four are more likely to suffer these injuries due to MVA; in 5-9 years old is more likely from auto-pedestrian accidents, and for 10-17 years old, due to bicycle related injuries. Half of all chest injuries are associated with other organ injuries including abdominal, extremity, head and pelvic injuries [3]. Balci et al. showed that mortality rate was $16 \%$ for two body regions and increased to $28 \%$ for multiple system injuries [5]. Sudden deceleration in MVA injures intrathoracic structures by impact against the sternum and ribs [4]. Pulmonary contusions are the most common injury seen in pediatric blunt chest trauma patients [5] and may lead to bleeding, edema, airway obstruction, impaired ventilation \&perfusion, and hypoxia [3]. This differs from the adult population, in whom pneumothorax, hemothorax and rib fractures are more common from blunt chest injury [6]. Therefore, diagnosing pediatric chest injuries can be difficult secondary to lack of external signs of trauma [4]. Nakayama et al. found that significant intrathoracic injury occurred in $52 \%$ of pediatric blunt chest trauma patients without associated rib fractures [7]. Due to increased compliance of the pediatric chest wall, the ribs are able to bend without breaking, and pneumothoraces may be overlooked in children [2,7]. Rare pediatric chest injuries include diaphragm rupture, heart contusions, flail chest, tracheobronchial disruption, great vessel injury, and esophageal rupture [5].

\section{Case Study}

A previously healthy 10 year-old girl with rollover MVA was transferred to our institution for possible aortic dissection; there were multiple fatalities at the scene. Upon arrival to the emergency department the patient complained of neck pain, headache, left shoulder \& knee pain and bilateral wrist pain. The patient had occipital and right parietal hematomas, C6-C7 tenderness to palpation (TTP), left periorbital contusion, left forehead laceration, bilateral wrist TTP, left shoulder and knee TTP with decreased range of motion, and a superficial vaginal laceration. There was no loss of consciousness. The patient had no previous medical problems. The vital signs were stable. Computed tomography (CT) of the brain showed a right temporal middle fossa parenchymal bleed; CT angiogram (CTA) of the chest was read as a Stanford type A aortic dissection with extension into the proximal innominate and left common carotid arteries (Figure 1 and 2). Consultation was made for aortic repair. Before proceeding to surgery, the risk of heparinization for cardiopulmonary bypass (CPB)

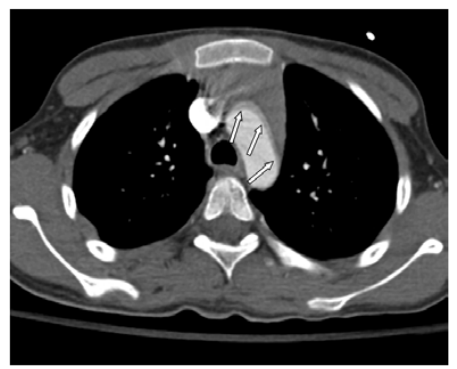

Figure 1: Images from CT aortogram, at the level of the arch, demonstrate a crescent-like density along the anterior aspect of the aorta, followed to the takeoff of the great vessels (arrows). There is no associated fracture of the thorax or mediastinal hematoma.

*Corresponding author: Muhammad Babur Rafique, Assistant Professor of Anesthesiology, University of Texas Health Science Center Houston, Houston, TX, Mailing Adress: 6431 Fannin St. MSB 5.020 Houston, TX 77030, USA, Tel: (713) 5006200; Fax: (713) 500-0528; E-mail: Muhammad.Rafique@uth.tmc.edu

Received May 27, 2013; Accepted June 27, 2013; Published June 30, 2013

Citation: Cameron SD, Gurur BD, Douglas WI, Srinivasan A, Rafique MB (2013) A Pediatric Aortic Dissection with Cerebral Bleed: A Review in Diagnosis and Management. J Blood Disorders Transf 4:144. doi:10.4172/2155-9864.1000144

Copyright: (c) 2013 Cameron SD, et al. This is an open-access article distributed under the terms of the Creative Commons Attribution License, which permits unrestricted use, distribution, and reproduction in any medium, provided the original author and source are credited. 
was discussed with the neurosurgery team, and it was decided that the small temporal fossa bleed was not significant enough to warrant a delay of aortic repair and decision to immediately proceed to the operating room.

After IV induction, airway was secured with an oral endotracheal tube with inline stabilization. General anesthesia (GA) was maintained with isoflurane at 1/2 MAC, fentanyl, and midazolam. An arterial line and central line were placed for invasive monitoring. Pre-operative transesophageal echocardiogram (TEE) showed no dissection (Figure 3); however, the transverse aortic arch was not visualized. Open mediastinal exploration and aortic ultrasound were performed. These showed no false lumen or dissection. Therefore, no further exploration was performed. Post-operative TEE showed a normal aortic root and a small posterior intimal flap (Figure 4). Patient was transferred to pediatric intensive care unit and was discharged to home on postoperative day three.

\section{Discussion}

Traumatic aortic dissection is rare in the pediatric population and is seen in less than $1 \%$ of trauma patients; only 9 pediatric aortic injuries have been diagnosed over the past ten years at our institution (a level 1 pediatric trauma center) [8]. Sudden deceleration, as occurs in MVAs, creates shear forces in intra-thoracic tissue that can result in hematoma, dissection, or rupture [4], as well as other solid organ injuries [9]. About $50-85 \%$ of traumatic aortic injuries from MVA are lethal $[1,10]$. Upon arrival to the hospital, $15-25 \%$ of those with traumatic aortic injury are alive [11].

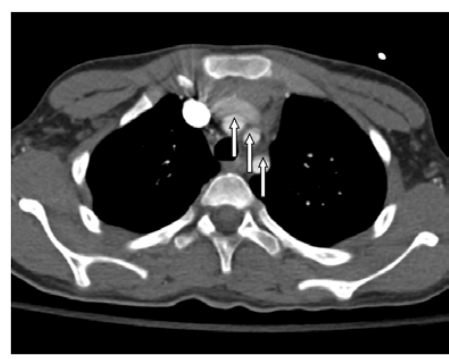

Figure 2: Image from CT aortogram at the aortic root again demonstrates the crescent-like density anteriorly (arrow), but a similar density is seen involving the main pulmonary artery (arrowhead), suggesting that both may be artifact due to cardiac motion.

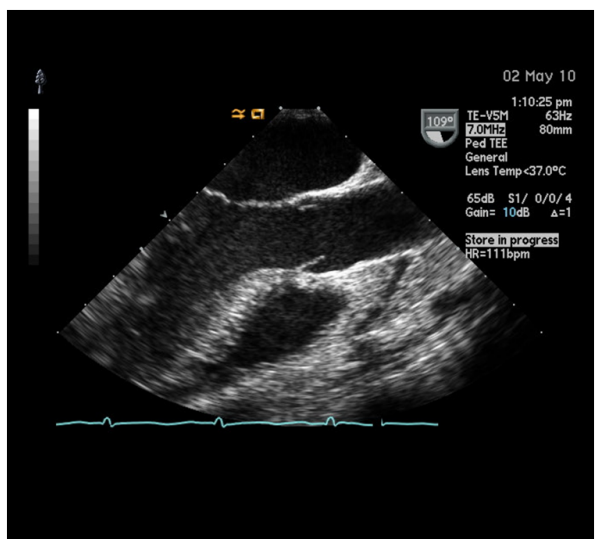

Figure 3: Pre-op TEE image showing aortic valve and ascending aorta in long axis. There was no dissection in the ascending aorta.

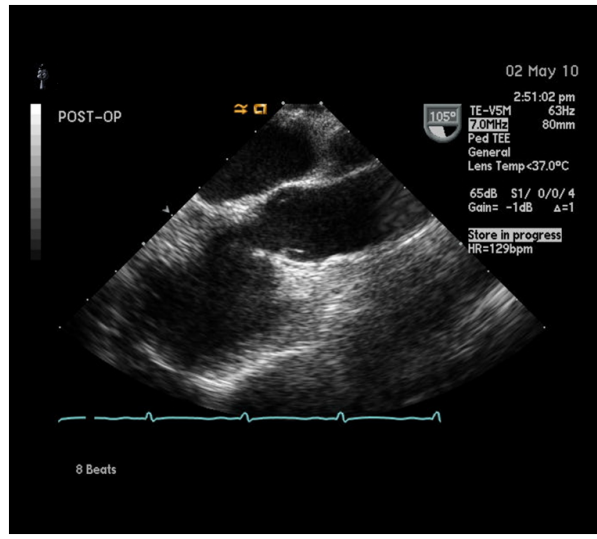

Figure 4: Post-op TEE image of aortic valve and ascending aorta in long axis. The ascending aorta looked normal without dissection.

Dissection occurs when a tear in the wall of the aorta allows blood to enter into a false lumen, thus separating the intimal and medial layers of the aortic wall. Close to $95 \%$ of traumatic dissections begin distal to the left subclavian artery where the isthmus is fixed to the left pulmonary artery by the ligamentumarteriosum. At this immobile point, the aorta undergoes force, while the more mobile ascending aorta and arch can move freely $[1,4,8]$. The Stanford and Debakey classification systems are used to describe aortic dissections. Stanford type A dissections involve the ascending aorta and aortic arch, and type B dissections involve the descending aorta. Type A dissections typically have a worse prognosis than Type B dissections.

Aortic dissections typically present with acute sharp pain in the anterior chest or back, depending on the location of the dissection. However, in a trauma patient, distracting injuries may mask chest pain. Ascending aorta dissections may present with chest pain radiating to the neck, while type $\mathrm{B}$ dissections may produce pain that radiates to the interscapular area [12]. As the dissection spreads due to hemodynamic shear forces, the pain may migrate, and other clinical findings may present as branches of the aorta become occluded, resulting in involvement of the gastrointestinal and renal systems. Patients may also complain of shortness of breath, hoarseness, anxiety, neck, or jaw pain. Neurological changes, such as syncope, may represent occlusion of the carotids. Other findings on exam may be tachycardia, unilateral decrease or absence of peripheral pulses, limb pain and weakness, and paraplegia in $2-5 \%$. A new precordial heart murmur may be heard on exam in $10-20 \%$ of patients.

Fatality usually results when the dissection spreads to the heart and causes pericardial tamponade. Ascending aortic dissections are thus considered a surgical emergency, as $90 \%$ of patients will die within three months if not corrected [4]. In trauma, mortality is $1 \%$ per hour for the first 48 hours in ascending dissections [1]. The International Registry of Acute Aortic Dissection (IRAD) has shown a mortality rate of $27 \%$ for those with ascending dissections that are treated surgically, compared to $57 \%$ who are medically managed [13]. Descending dissections have a better survival rate [4].

Typically, the chest radiograph is the first diagnostic test done, and may show a widened mediastinum, obliteration of the aortic knob and contour, depressed left mainstem bronchus, apical capping, sternal or first rib fracture, massive left sided hemothorax, blunting of 
the diaphragm, and a deviated trachea or esophagus [1]. One study of pediatric thoracic aortic injuries found that the most frequent finding on chest X-ray (94\%) was a prominent or indistinct aortic knob [14]. Five to $12 \%$ of chest radiographs will be normal [13]

EKG findings are usually nonspecific. The mechanism of injury, exam findings, and a high index of suspicion should prompt further investigations to look for aortic disruption in the pediatric population, wherein many physical signs may be absent. Aortography has traditionally been regarded as the "gold standard" for diagnosing aortic dissections; however, due to its invasiveness, risk of further aortic injury, nephrotoxicity, and diagnostic delay, its use has fallen out of favor during these emergent situations [15], favoring the use of CTA, TEE with color doppler, and magnetic resonance imaging (MRI).

CTA is now considered the preferred screening test in most trauma centers [1] if the patient is stable $[14,16]$. CTA can quickly detect intimal flaps, false lumens, pseudoaneurysms, displaced aortic calcifications, contour irregularity, aortic widening, and extravasation of contrast material, with sensitivities greater than $90 \%$, and specificities greater than $85 \%[15,17]$. An additional advantage is that CT can be used to detect other traumatic injuries. Various pitfalls assessing CT angiograms for dissection have been described in the literature. Difficulty in diagnosis with CTA may be due to motion artifacts and poor contrast enhancement [15]; as seen in our case, the diagnosis of type A aortic dissection was false-positive. This appearance is thought to be due to cardiac motion artifact (Figure 1 and 2). Although this artifact may be avoided by using cardiac gating during the scan, the appearance of such significant motion artifacts easier is lessened with the utilization of faster multi detector CT scanners.

While CTA offers the ability to visualize branches of the aorta that may be compromised, TEE is a more rapid approach for emergent diagnosis, especially in a hemodynamically unstable patient who may not have time to undergo CTA. Erbel et al. showed that TEE was faster and superior to aortography and CT for detecting aortic injury [18]. TEE is associated with less expense and fewer neurologic and renal complications than other modalities [19], and it is easily portable. TEE can detect a mobile intimal flap, flow within a false lumen, wall hematomas, aortic occlusion, aneurysm, and as little as $30 \mathrm{ml}$ of pericardial effusion $[1,15]$. A false lumen will collapse during systole, while the true lumen collapses during diastole. Vignon et al. showed that a $7 \mathrm{~mm}$ gap between the probe and aorta, plus blood between the aorta and pleural space are strong predictors of aortic disruption [20]. A distance of more than $1 \mathrm{~cm}$ between the aorta and esophagus likely indicates mediastinal hematoma [15]. Intimal tears are "mobile intraluminal appendages" usually seen without a turbulent blood flow pattern, and can be managed conservatively $[20,21]$. The sensitivity and specificity of TEE have been reported to be $89 \%$ and $88 \%$, respectively [15]. Diagnostic difficulty with TEE may arise when trachea obstructs views of the distal ascending aorta, proximal aortic arch, branch vessels, and descending aorta $[14,19]$. TEE also requires an experienced observer as artifacts may mimic a true aortic flap [22]. Patient sedation is required, in comparison to CTA.

Although MRI has a sensitivity and specificity close to $100 \%$, it is usually not quickly accessible on an emergent basis [15]; however, it can be used for follow-up imaging during medical management of stable aortic injuries, and it has the added benefit of avoiding ionizing radiation and the associated risk of carcinogenesis [23].

Medical management of aortic dissections entails pain control and strict blood pressure control, especially during anesthetic induction and laryngoscopy, to prevent increases in intraluminal pressure, spread of dissection and possible rupture. Beta blockers, nitroglycerin, and sodium nitroprusside, with a right radial arterial line and central venous line can be used for hemodynamic control and monitoring. Most guidelines indicate that systolic blood pressure should be monitored in both upper extremities and kept between 90-100 $\mathrm{mmHg}$, and heart rate is not to exceed 100 beats per minute [19]. In the pediatric population, studies have shown that patients presenting with systolic blood pressures of less than $90 \mathrm{mmHg}$ have increased morbidity and mortality [8], emphasizing the importance of strict blood pressure control.

Traumatic aortic injury patients carry a risk for rupture, and it is recommended that they be repaired surgically. However, several cases of successful non-operative management have been reported. One ten year study reported that 3 of 7 pediatric patients with thoracic aortic injury ( 2 intimal flap tears and 1 pseudoaneurysm) were successfully managed nonoperatively [9]. In another report, 2 patients presented with cerebral contusions and ascending aortic transections, and due to the risk of heparinization, surgery was delayed and repeat CT scans showed stable findings [24]. Other conditions may necessitate delayed surgical repair: intracranial hemorrhage, uncertain prognosis related to comorbid conditions (such as intraabdominal hemorrhage needing emergent laparotomy), sepsis, thermal injury, or severe lung contusion and hypoxia [25]. Especially even a small intracranial hemorrhage can become large due to anticoagulation with heparin (or its substitutes like hirudin, argatroban etc.) needed for cardiopulmonary bypass institution; to date no anticoagulation agents are available which can be used intitutingcardiopulmoanary bypass and do not increase risk of existing intracranial hematoma expansion.

When an initial study, such as chest radiograph, CTA, TEE, or MRI is equivocal, then subsequent studies should be performed to assess for aortic injury. Similar to this case, a report by Scaglione et al. [17] described 2 false positive cases of aortic injury misdiagnosed by CT, attributable to linear motion artifact and cardiovascular pulsations. The authors recommend thoracic aortography in the event of a possible artifact, especially when mediastinal hematoma is absent [17]. A separate study determined that indeterminate CTAs (mediastinal hematoma without aortic injury) may not need aortography, as aortic injury is unlikely [26]. When CT is positive for aortic dissection but the TEE is negative in a hemodynamically stable patient, close medical management may be considered [27]. However, given the rarity of traumatic aortic dissection in the pediatric population, particularly in patients without cardiovascular disease or a collagen disorder (e.g. Marfan or Ehlers-Danlos Syndromes), disagreement between imaging modalities in a clinically stable patient should result in strong consideration for further imaging evaluation before operative intervention.

\section{References}

1. Jaffe RA, Samuels SI (2009) Anesthesiologist's Manual of Surgical Procedures (4thedn), Philadelphia: Lippincott.

2. Cote CJ, Lerman J, Todres ID (2009) A practice of Anesthesia for Infants and Children. 4th ed. Philadelphia: Saunders.

3. Deng X, Yang Y, Deng Z, Huang E (2008) Experiences in severe chest trauma of children in 20 years. Interact Cardiovasc Thorac Surg 7: 1031-1034

4. Hines RL, Marschall KE (2008) Stoelting's Anesthesia and Co-Existing Disease. 5 th ed. Philadelphia: Churchill Livingstone.

5. Balci AE, Kazez A, Eren S, Ayan E, Ozalp K, et al. (2004) Blunt thoracic trauma in children: review of 137 cases. Eur J Cardiothorac Surg 26: 387-392. 
Citation: Cameron SD, Gurur BD, Douglas WI, Srinivasan A, Rafique MB (2013) A Pediatric Aortic Dissection with Cerebral Bleed: A Review in Diagnosis and Management. J Blood Disorders Transf 4:144. doi:10.4172/2155-9864.1000144

Page 4 of 4

6. Demirhan R, Onan B, Oz K, Halezeroglu S (2009) Comprehensive analysis of 4205 patients with chest trauma: a 10-year experience. Interact Cardiovasc Thorac Surg 9: 450-453.

7. Nakayama DK, Ramenofsky ML, Rowe MI (1989) Chest injuries in childhood Ann Surg 210: 770-775.

8. Allison ND, Anderson CM, Shah SK, Lally KP, Hayes-Jordan A, et al. (2009) Outcomes of truncal vascular injuries in children. J Pediatr Surg 44: 1958-1964.

9. Anderson SA, Day M, Chen MK, Huber T, Lottenberg LL, et al. (2008) Traumatic aortic injuries in the pediatric population. J Pediatr Surg 43: 1077-1081.

10. Barmparas G, Inaba K, Talving P, David JS, Lam L, et al. (2010) Pediatric vs adult vascular trauma: a National Trauma Databank review. J Pediatr Surg 45: 1404-1412.

11. Lin PH, Bush RL, Zhou W, Peden EK, Lumsden AB (2006) Endovascular treatment of traumatic thoracic aortic injury--should this be the new standard of treatment? J Vasc Surg 43 Suppl A: 22A-29A.

12. Thrumurthy SG, Karthikesalingam A, Patterson BO, Holt PJ, Thompson MM (2011) The diagnosis and management of aortic dissection. BMJ 344: d8290.

13. Hagan PG, Nienaber CA, Isselbacher EM, Bruckman D, Karavite DJ, et al (2000) The International Registry of Acute Aortic Dissection (IRAD): new insights into an old disease. JAMA 283: 897-903

14. Pabon-Ramos WM, Williams DM, Strouse PJ (2010) Radiologic evaluation of blunt thoracic aortic injury in pediatric patients. AJR Am J Roentgenol 194 1197-1203.

15. Erbel R, Alfonso F, Boileau C, Dirsch O, Eber B, et al. (2001) Diagnosis and management of aortic dissection. Eur Heart J 22: 1642-1681.

16. Patterson BO, Holt PJ, Cleanthis M, Tai N, Carrell T, et al. (2012) Imaging vascular trauma. Br J Surg 99: 494-505.

17. Scaglione M, Pinto A, Pinto F, Romano L, Ragozzino A, et al. (2001) Role of contrast-enhanced helical CT in the evaluation of acute thoracic aortic injuries after blunt chest trauma. Eur Radiol. 11: 2444- 2448.

18. Erbel R, Engberding R, Daniel W, Roelandt J, Visser C, et al. (1989) Echocardiography in diagnosis of aortic dissection. Lancet 1: 457-461.

19. Miller RD (2010) Miller's Anesthesia. (7thedn), Philadelphia: Churchill Livingstone;

20. Vignon P, Guéret $P$, Vedrinne JM, Lagrange P, Cornu E, et al. (1995) Role of transesophageal echocardiography in the diagnosis and management of traumatic aortic disruption. Circulation 92: 2959-2968.

21. Goarin JP, Cluzel P, Gosgnach M, Lamine K, Coriat P, et al. (2000) Evaluation of transesophageal echocardiography for diagnosis of traumatic aortic injury Anesthesiology 93: 1373-1377.

22. Vignon P, Spencer KT, Rambaud G, Preux PM, Krauss D, et al. (2001) Differential transesophageal echocardiographic diagnosis between linear artifacts and intraluminal flap of aortic dissection or disruption. Chest. 119: 1778-1790.

23. Flamm SD (2007) Cross-sectional imaging studies: what can we learn and what do we need to know? Semin Vasc Surg 20: 108-114.

24. Wall MJ Jr, Tsai PI, Gilani R, Mattox KL (2010) Challenges in the diagnosis and management of unusual presentations of blunt injury to the ascending aorta and aortic sinuses. J Surg Res 163: 176-178.

25. Takach TJ, Anstadt MP, Moore HV (2005) Pediatric aortic disruption. Tex Heart Inst J 32: 16-20

26. Sammer M, Wang E, Blackmore CC, Burdick TR, Hollingworth W (2007) Indeterminate CT angiography in blunt thoracic trauma: is CT angiography enough? AJR Am J Roentgenol 189: 603-608.

27. Trachiotis GD, Sell JE, Pearson GD, Martin GR, Midgley FM (1996) Traumatic thoracic aortic rupture in the pediatric patient. Ann Thorac Surg 62: 724-731.
Citation: Cameron SD, Gurur BD, Douglas WI, Srinivasan A, Rafique MB (2013) A Pediatric Aortic Dissection with Cerebral Bleed: A Review in Diagnosis and Management. J Blood Disorders Transf 4:144. doi:10.4172/21559864.1000144 